\title{
DEVELOPMENT OF VOCABULARY IN CHILDREN WITH INTELLECTUAL DISABLLTIES
}

Sarmīte Tūbele ${ }^{1}$, Evija Landrāte ${ }^{2}$

Překlad tohoto článku do češtiny si můžete prečíst zde.

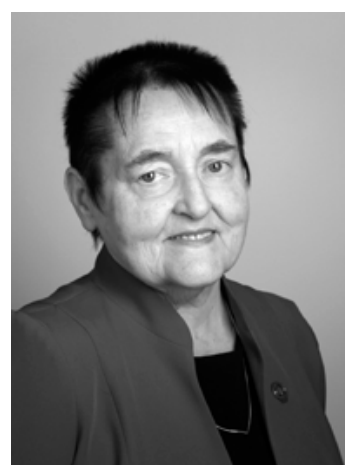

Sarmìte Tūbele

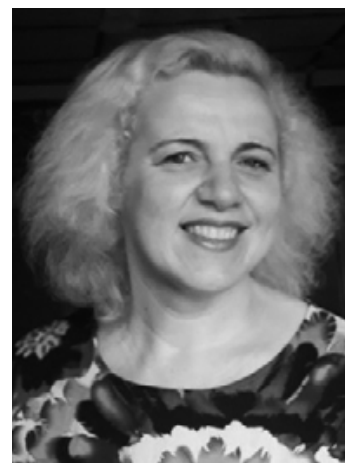

Evija Landrāte

\section{Abstract}

The article "Development of Vocabulary in Children with Intellectual Disabilities" is intended to reveal some incidences in a Speech Therapist's work in one of the special schools in Latvia. Individual sessions are held for younger children. Although groups are not large, working with even four students is a challenge for the Speech Therapist. As communication is essential for humans, the Speech Therapist must work towards the enrichment of the vocabulary of every student, even those with moderate or severe intellectual disabilities (or in combination with Autism Spectrum Disorder).

This study aims to determine the possibilities for the enrichment of vocabulary. The results show the effect of the chosen methods used by the Speech Therapist. Nevertheless, these results are not very impressive, taking into account the characteristics of the students.

\section{Keywords}

intellectual disability, enrichment of vocabulary, Speech Therapist, Autism Spectrum Disorders

\section{Introduction}

Verbal communication is an affirmation of the human essence. The ability to speak is genetically inherited, but the child's ability to speak is realised only through communication where all the senses and cognitive processes are involved. Despite the great advancements in technology of our century, children with serious health problems, including intellectual disabilities, are still being born. This significantly influences and hinders the child's overall development, including language development. According to some researchers, disorders tend to increase (Schwartz, 2017; Da Fonte, \& Boesch, 2018; Karveliene, 2019).

Despite each child being special to his or her family, society also has to be involved in the support to ensure the child's participation in everyday life. For children with moderate to severe intellectual disabilities, this process is much more complex. Although their general and especially language development is distorted, their possibilities are individually different. Purposeful work with a Speech Therapist can widen the perspective of communication. Enrichment of the vocabulary in children with intellectual disabilities will affect other language skills and will be a prerequisite for a more successful integration into society.

Not a lot of data is available on the intervention and specific vocabulary expansion methods for children with intellectual disabilities. The authors wanted to present the successful teamwork of teachers, parents, a Psychologist, a Physiotherapist, a Social Pedagogue and a Speech Therapist, but on this occasion only the Speech Therapist's work will be analysed. It is the responsibility of the Speech Therapist to examine, evaluate, and carry out corrective action/intervention to achieve significant improvement in children's speech and language deficits (Lūse, Miltiņa \& Tūbele, 2012). At the same time, the strengths of a child must be taken into account to create a positive and favourable environment for reaching the goal - improvement of communication (Miltiña, 2008; 2019; Tūbele, 2019).

Aim of the research is to reveal and test the methods of enrichment of the vocabulary of children with moderate and severe intellectual disabilities in Speech Therapy sessions.

\footnotetext{
Faculty of Education, Psychology and Art, University of Latvia, Imantas 7. linija 1, Riga, Latvia.

2 Corresponding author: Prof. Dr. paed. Sarmite Tübele, Faculty of Education, Psychology and Art, University of Latvia, Imantas 7. līnija 1, Riga, Latvia. E-mail: tubele@gmail.com.
} 
Research methods used: analysis of scientific literature in the research field; evaluation and testing (self-assessment) vocabulary in children with moderate and severe mental retardation; repeated testing after intervention; quantitative and qualitative data processing and analysis.

\section{Theoretical framework}

\section{Speech and Language}

By learning a language, a child is able to connect with other people and to express his/her thoughts. With the aid of language, the child acquires knowledge of the world around him and its processes. Speech is considered personal, but language is a system of social signs (F. De Saussure, cited in Kūlis \& Kūle, 1998). Both can develop only in human society. The word as a whole is one of the basic elements of language. The word, with its sound and meaning, forms a definite, indivisible unit. As a child enters this world, he slowly begins to master the entirety of a language - sounds, syllables are imitated, then words, their meanings are memorised, and sentences are learned (Laua, 1981). The word has several functions. It can be used to denote objects, phenomena; to evoke their images, to accentuate and classify their essential features (Giles, 2002). A word can be both a conceptual tool and a result of it (Kl̦avinina, 1997).

A person acquires language in connection with thinking, memory, perception and other cognitive processes. It has a very close connection with thinking. $L$. Vygotskis has stated this as the essential way of thought being transformed into words and becoming speech (Vigotskis, 2002). Every human perceptual, mental and motor/physical function is processed by the brain (Giles, 2002). Neuro-imaging studies indicate that distinct brain regions are activated during language processing (Hillis, 2001; Giles, 2002). It is obvious that there is a tight correlation between language acquisition and the development of cognitive processes. If there are signs of underdevelopment in any of these areas, the impact is apparent.

One of the basic features of cognitive development is memory. Psychologists define three main types of memory sensory memory, short-term or working memory, and long-term memory (Giles, 2002). Short-term memory presents the most problems for children with mental retardation.
Vocabulary development is a process by which children acquire the meaning of things and processes and learn to communicate. Without words, we cannot build sentences, we cannot understand ongoing processes and participate in them. Scientists have stated the typical development and approximate number of words at specific ages (Hemphill \& Tivnan, 2008; Miltina, 2008; Song, Demuth \& Morgan, 2918). There are findings that vocabulary is crucial for later literacy (Marjanovič-Umek, Fekonja-Peklaj \& Podlesek, 2012; Zubrick, Taylor \& Christensen, 2015; Moody, Hu, Kuo, Jouhar, Xu \& Lee, 2018). Therefore, children with intellectual disabilities are in the group at risk.

The most intensive development of language takes place from birth to 4 - 5 years of age. Quantitative and qualitative manifestations are influenced by many factors: environment (Elnebija, 1990), attitude of family and others (Irbe \& Lindenberga, 2017), health conditions (Jelliffe-Pawlowski, Shaw, Nelson \& Harris, 2003; Korkmaz, 2011), and the development of the child (Liepina, 2008; Bornstein, Hahn, Putnick \& Pearson, 2018; Short, Eadie \& Kemp, 2019). The development of vocabulary is a step-by-step process, with one of the first stages being the comprehension of words. The development of vocabulary is also a task for speech and language therapists, and it is possible to improve the situation with specific exercises and materials.

\section{Intellectual Disability}

Intellectual disability is characterised as the condition when individuals show significant deficits in cognitive processes, adaptive functioning (conceptual, social and practical). There are four stages of severity of intellectual disability - mild, moderate, severe, and profound. Children involved in this research suffer from moderate and severe intellectual disabilities. This means that their developmental possibilities are limited. The curriculum for these children is based mainly on an individual approach according to the needs of the children (Liepina, 2008; Prudnikova, 2012).

We are still using ICD-10 (International Classification of Diseases), but look forward to using ICD-11. Intellectual disabilities are increasingly being understood as an outcome of adverse influences on the developing brain, and hence as much a biomedical condition as a psychological construct based on intelligence and adaptive abilities. The developmental nature of intellectual disabilities has also been emphasised, either implicitly, or more explicitly in earlier classifications (Girimaji \& Pradeep, 2018).

Practitioners working with these children need to have an in-depth knowledge of all the peculiarities and characteristics of their disabilities.

One of the main problems is disorder in all cognitive processes, and limited capabilities of working, perception and understanding. Memorising is mechanical and very slow. Children with intellectual disabilities cannot concentrate their attention; the attention span is short, and it is difficult to capture the attention. There is no interest in the surrounding objects, or in the environment; weak observational skills, as well as spatial and time perception. There is a lack of interest and understanding of images; poor emotions, will and initiative. Distinct problems concern communication, speech development and language acquisition in general - there is a limited vocabulary and limitations in its usage. As there are difficulties in using acquired knowledge in a new situation, learning vocabulary is an arduous process (Pruthi, 2013; Bornstein, Hahn, Putnick \& Pearson, 2018).

There are several common features that characterise children with intellectual disabilities.

> Cognitive dysfunction is comprehensive, with even both verbal and non-verbal tasks being difficult.

> There are very weak generalisation abilities; children are unable to model tasks; they can solve them only in specific situations.

> There are correlations between intellectual disabilities and disabilities in behavioural, emotional, and volitional areas.

> There is a very low cognitive interest and an uncritical attitude towards oneself and towards the result of one's work.

> Difficulties in predicting the consequences of actions; inability to think and plan, lack of focus that hinders development.

> Poor curiosity (Liepina, 2008; Korkmaz, 2011; Shree \& Shukla, 2016).

The most important factors that can influence the occurrence of intellectual disabilities are: adverse effects of environmental factors; unsuccessful course of pregnancy; birth process; health status (chromosomal abnormalities, brain diseases, foetal malformations or disorders of unknown 
origin); health and quality of life in the first years of life (Jelliffe-Pawlowski, Shaw, Nelson \& Harris, 2003; Liepiña, 2008; Shree \& Shukla, 2016).

As a result, children with intellectual disabilities develop at a much slower rate, needing support and assistance, especially in the language field. Children with moderate to severe intellectual disabilities have particular difficulties. They need constant help and support. The main task is to teach the skills and abilities needed in everyday life (Geidžs \& Berliners, 1998; Prudņikova, 2012).

The condition is usually exacerbated by the fact that intellectual disability is rarely found in its pure form in moderate to severe cases. Visual, hearing, language, or autistic spectrum features are common, therefore multifunctional disorders are more frequent. In this case, the structure of the interference is complex, and the structural elements interact. Movement disorders that affect motor development can also be found. The intellectual abilities of these children are far behind in their development, with the biological age of these children not matching their cognitive age.

Due to cerebral dysfunction, these children have an inadequate response to sensory irritation. The tactile sensation is underdeveloped, making it difficult to get to know object and the environment; they are unable to perform comparative actions, they cannot differentiate between people, things, different concepts (here - there; now - later; more - less). It is difficult to develop an understanding of abstract items. This must be taken into account when developing vocabulary. Children with moderate and severe intellectual disabilities will always have a limited idea of what is happening around them. The difficulty of expressing themselves in words will also remain.

Based on the findings of various authors (Liepina, 2008; Korkmaz, 2011; Shree \& Shukla, 2016; Bornstein et al., 2018), a table was compiled that summarises the most common characteristics in several domains for children with moderate to severe intellectual disabilities (see Table 1).
Feelings and perception

Attention

Memory

Emotions, will, social contact, behaviour

Expression of thinking in language
Often the senses do not correspond to the situation, they are disturbed. There may be increased or decreased sensitivity.

It only develops as a result of vivid impressions. Unintentional attention dominates. Usually only a bright, moving object or significant sound attracts attention.

Mechanical memory based on associative feelings predominates. Not able to memorise long-term, quickly forgotten.

Hard-to-find, inherent lack of curiosity, often shows no interest in what is around or what is happening. Does not know how to play, does not understand how to manipulate toys. Can make uniform, irrelevant and aimless movements. Characteristic emotional imbalances tend to be unpredictable.

These children can show inadequate disobedience and their

behaviour can be challenging. Some of them tend to be aggressive, others - crying, harassing or fearful.

They often do not feel the need to communicate with other peers.

In the learning process, it is only on the basis of demonstrably practical thinking that separate thinking processes are formed. Comparing and classifying objects is problematic. Unable to perform analysis. Language not developed, pronunciation disorders, grammatical problems. Some of them lack language, only different sounds are uttered. Often words are repeated mechanically without understanding their meaning. Often they only partially understand or do not understand the teacher's instructions and are unable to answer questions.

Table 1: Essential Features of Cognitive Process, Emotions, Will, Social Contact, and Behaviour in Children with Moderate to Severe Intellectual Disability (after Liepina, 2008; Korkmaz, 2011; Shree \& Shukla, 2016; Bornstein et al., 2018)

This table illustrates very clearly that the extent of the general level of development of children with moderate to severe intellectual disabilities, including language and speech development, is below average, when language and speech proficiency can be compared to approximately normal adult development.

In order to make some insignificant progress in a skill area, professionals working with these children, including the Speech Therapist, need a great deal of patience. Despite severe developmental disabilities, students with moderate to severe intellectual disabilities can learn a variety of skills. However, this takes a great deal of time, sometimes even years. 
Some authors who point out the special features of children with intellectual and language acquisition disabilities, conclude that one of the most important characteristics of intellectual disability is the lack of comprehensive speech and language development (Liepina, 2008; Korkmaz, 2011; Pruthi, 2013). Nevertheless, as other authors point out, for students with moderate to severe intellectual disabilities, speech comprehension can be very primitive, preserved only on a social level. The vocabulary of the language is poor, and its development is very limited (Akhtar \& Gernsbacher, 2007; Shree \& Shukla, 2016; Bornstein et al., 2018).

Difficulties with language acquisition could be due to the specific features of speech and language development, which are well characterised by several authors, emphasising that in these students:

> Speech and language learning tend to start much later;

> Adult speech also begins to be delayed;

> There is difficulty in understanding the meaning of the word;

> Due to their sluggish nature, they often do not speak "unnecessarily" without naming items in words;

> There are very poor imitation skills;

> There is use of autonomous speech that is understood only by those closest to them;

$>$ Both motor anxiety and motor disorders are observed, which tend to interact with speech disorders;

> They tend to be very sedentary and passive, which slows down their learning of the environment, which in turn influences the process of learning new words.

Sometimes the psychological barrier formed for various reasons hinders the expression of these children (Liepina, 2008; Prudnikova, 2012; Bornstein et al., 2018).

The developmental disability specificity of children with moderate and severe intellectual disabilities limits their effective language development. As a result, these children may never acquire the ability to use verbal means of expression in their communication. However, if they master it, their speech will be vague, with a limited grammatical linguistic structure. These children will also not be able to understand the causal relationships between different processes, and their active functioning will not be regulated through productive language.

The task of a Speech Therapist in dealing with these students is far from simple.
The most important skills needed to be developed by a Speech Therapist when working with these children are the purposeful development of communication and communication processes, which undoubtedly includes the potential for expanding the individual vocabulary.

\section{Autism Spectrum Disorders}

Autism Spectrum Disorder (ASD) is a complicated condition, which is manifested differently in each child (Singletary, 2015). The abilities of children with ASD are often on different levels, so teachers usually face challenges in effectively coping and working with students with ASD (Reagan, 2012). The Diagnostic and Statistical Manual of Mental Disorders, $5^{\text {th }}$ Edition (DSM-5) considers ASD in two general domains: as social communication impairment, and as repetitive/restricted behaviours (American Psychiatric Association, 2018). One of the main problems in diagnosing ASD is to have an appropriate early diagnosis while the child is at the school age. Research suggests that assessment of functional skills is crucial in creating an Individual Educational Programme and selecting the necessary services and support, adaptations, and accommodations (Esler \& Ruble, 2015). Deficits in social communication for children with ASD are linked to their ability to express themselves. They are misunderstood, hence the teacher needs to find successful strategies for collaboration that will overcome these communication barriers (Perepa, 2014). In mainstream schools, many students with ASD are considered as students with learning disabilities, in need of specific help and support. This is associated with the great impact of Autism on the learning process of a child. Nevertheless, there is good evidence that adaptive behaviour is more severely impaired in individuals with Autism (O'Brien \& Pearson, 2004). Learning disability inevitably impacts social communication, which leads to stereotyped behaviour and can result in more complicated problems. Some of these issues are attachment difficulties and the lack of strategies for cooperation in a child with ASD. Studies have shown that children with Autism exhibit more attachment insecurity than typical children, therefore they require specific support (McKenzie \& Dallos, 2017). To overcome attachment difficulties, researchers offer different strategies, including manualised interpersonal problem-solving skills (Bonete et al., 2016), observational learning (Taylor \&
DeQuizio, 2012), receptive language organisation (Frye \& Beuchamp, 2009), assistive technologies to enhance language skills (Fteiha, 2016), and adaptive treatment strategy (Shih, Patterson \& Kasari, 2016). Regardless of the strategy, in conditions where students with ASD enjoy full understanding and support, they can develop properly, and can achieve well-being in everyday life and schooling (if they are not hindered by other disabilities or a combination of them). However, a system of elements, containing organisation of the classroom environment, basic instructional strategies and visual aids, individual learning, and behaviour support has to exist in their learning environment (Koenig et al., 2014). Furthermore, if one strategy does not work, another needs to be tested, or the approach needs to combine favourable elements of different strategies (Vivanti, 2017). It is necessary to add that an inclusive setting alone is not enough for the appropriate development of children with ASD (Aller, 2017).

The aim of this article is to demonstrate the actions of a Speech Therapist in a class (group) that includes four pupils with intellectual disabilities. Characteristics of Autism in two of the children define the specifics of the work. However, in this case it is treated as a group with severe intellectual disabilities. This group provides children with the opportunity to develop specific communication abilities (Tūbele, 2019; Landrāte \& Tūbele, 2019).

\section{Research Process}

Intervention in children with intellectual disabilities is very complicated, because of cognitive impairment and delayed development in all areas, especially in speech and language acquisition. It is more complicated when the level of intellectual disability is moderate or severe. Children with a moderate intellectual disability can communicate, but only in a simple manner, not on a complex level. In everyday life, they can sometimes live independently, although there are situations when help and support are still needed.

If intellectual disability is on a severe level, there are considerable delays in their development and their ability to communicate is on a very low level; some of them need support and require the use of alternative or augmentative communication tools.

It is complicated to provide a wholesome language acquirement process for students with intellectual disabilities, because of insufficient development of 
cognitive processes, weakness of the will, and other characteristics. Many authors suggest that, for the successful development of speech and language, there are prerequisites to be developed: qualitative functioning of peripheral speech apparatus - tongue, lips, soft palate and breathing (Marrus \& Hall, 2018; Short, Eadie \& Kemp, 2019), as well as other characteristics linked with cognitive processes. Taking into account findings about the development of students with moderate and severe intellectual disabilities, the Speech Therapist must make great efforts. It is a challenge! One of the prerequisites are positive emotions used as an intensifier in Speech Therapy sessions. Every session needs some support points:

$>$ positive emotional support;

$>$ multisensory approach;

> stimuli for the joy of activities;

$>$ possibility of freedom;

$>$ use of technologies;

> development of all cognitive processes;

$>$ promotion of cognitive activity and curiosity (Prudnikova,

2012; Tūbele, 2019).

Results will be achieved if the Speech Therapist takes into account all suggestions and evaluates every child's abilities properly. Evaluation is a process where the Speech Therapist, together with other involved persons, stipulates the necessary data to plan intervention activities. It is very important to identify strengths (Tübele, 2019), because this is the starting point of success. We also have to evaluate the possibilities and weaknesses in order to identify the goals for every child - will it be possible for him to speak, or do we have to find other means of communication?

Research was carried out in an educational institution - a developmental centre for children with moderate and severe intellectual disabilities. At first evaluation, children were observed in their activities and existing vocabulary. Later, the intervention plan was worked out with activities to promote the formation of an active and passive vocabulary for each child, using insight into each child's characteristics. Four children participated. Their names have been changed for ethical purposes.

Anna, 14 years old, diagnosed with severe intellectual disability and Autism Spectrum Disorder.

She is positively oriented, few interests. She likes walking, listening to music, handling water. During lessons, activities are possible only together with the teacher. Concentration of attention for a short period of time; memory is weak and unstable, motivation very low. Anna has no interest in learning, often protests at everything. With help, the girl imitates some movements - grabs and releases objects, transfers them from one container to another. Likes to work with materials of different structure - sand, shells, cones, chestnuts; likes tasks with sounds. She can push the key of synthesizer or sounding toy only with help, but, when done, listens to audible sounds. When she likes these sounds, she shows emotions with her body movements and by hand clapping.

Self-care skills are very poor: unable to dress and self-care, uses Pampers. Eats only food she likes - especially white bread and butter. Anna has no reaction to adults; if they want to draw her attention, the girl does not respond, rarely looks at the speaker; short-term eye contact. Any effort is perceived as discomfort. Often her desires are impatient - with aggressive crying, sometimes self-aggression - biting her hands, twitching her legs.

The girl's language functions are not developing. Language is not used as a means of communication; her needs are expressed by gestures or non-articulated sounds. Understanding of language is poorly developed, rarely responds to her name. It is not clear whether she understands simple phrases that are used in everyday life. She does not respond to questions and shows dissatisfaction.

Maria, 14 years of age; diagnosed with Down's syndrome and moderate intellectual disabilities.

The learning process with Maria is carried out individually. She is happy to carry out all the teaching tasks and suggestions. The girl is poorly mobilised for a task when an adult is not sitting next to her; then she limps, gets up, tries to leave the work space.

Self-care skills are well developed; she takes off outdoor clothes and shoes, uses the toilet, washes her hands. Help is needed when dressing, fastening fasteners, putting on clothes and shoes.

The girl is mostly positive. Communicates freely with classmates, often in an aggressive way - harassing others when they do not want to communicate, stalking them, commanding, pushing, taking away toys, and thus causing a conflict. Maria enjoys attending school events, loves being around people. Demonstrates willingness to participate in all activities without being able to distance herself. Sometimes the girl's behaviour is influenced by the events and emotions of the moment. Then she starts to stumble and refuses to do any task. In school, the girl's attention is relatively unsteady, and she has difficulty in switching, dividing and concentrating the attention.

She has learned and successfully uses the lesson plan - communication card system in her work; knows daytime activities comparatively well. She knows how to change dates in the calendar, how to move the weekday labels. She has the skills to assemble simple puzzles of up to 20 pieces. Poorly developed fine motor skills of the fingers. Imitates movements well. Communication with Maria is carried out using language, but her vocabulary is limited. Sentences are short, words are not aligned; sometimes she doesn't understand the meaning of the words. Her passive vocabulary has more units than the active vocabulary. Listens to and understands simple instructions and contemplates verbal information for a long time. Questions are answered with one word. Maria is able to learn a short poem, if it is also displayed with movements. The girl is able to repeat simple non-expanded sentences by example. She can name some of the objects in the pictures. Actions and properties are not named; she does not associate colours with their names. The girl has a poor perception of differences in the outline of letters, and sometimes is able to form words from separate block letters in a pattern.

Peter, 10 years old. Diagnosis - severe intellectual disability.

Attention is not stable and the boy loses attention. He switches poorly from one task or activity to another. $\mathrm{He}$ is not able to act independently on purpose. Self-care skills are poorly developed; he is accustomed to being caredfor and does not want to act on his own, waits for help and encouragement. Visits toilet with help and needs assistance in dressing after a toilet visit. The unbuttoned outerwear can be pulled off independently, but he is unable to dress himself independently.

Learning with the pupil is done individually. His cognitive interests are limited. His work is burdened by his emotional instability and imbalance. The boy is very sensitive and used to constant assistance. When adults talk in a friendly manner during the learning process, Peter perceives the activity as a game and there is no productive learning process. If the teacher speaks louder, the boy is scared, withdraws into himself, and cannot do anything. Therefore, it is good to find a balance 
between friendliness and rigour to facilitate the learning process.

With help, the boy is able to group simple objects which are obviously different in shape and size; he cannot differentiate colours. With the help of an adult, simple Segen boards are assembled. Peter has poorly developed fine motor skills. Completing tasks that require grabbing small items is difficult. Sometimes motor anxiety is present.

Peter does not speak, his language understanding is limited. Sometimes simple instructions are perceived, sometimes not. Responds to a change in adult's voice intonation. In order to comprehend what is said, it is necessary to reinforce it with gestures and movements that complement verbal information. Peter simulates facial expressions, gestures, movements. Both the passive and active vocabulary are very limited.

George, 10 years old. Diagnosis - moderate intellectual disability with features of Autism Spectrum Disorder.

During school lessons, the boy's attention is unsteady, and he often has difficulty to switch, divide and concentrate the attention. If the tasks do not require much intellectual effort, the boy becomes more open and participative. Georg has trouble controlling and regulating his behaviour, emotional reactions. Impulsive and inadequate reactions can be predicted. Frequent mood swings: if he is happy - laughs out loud, runs; if he doesn't like something - screams.

Every day he carries a magazine or paper, which he tears up by himself into small pieces. Self-care skills are relatively well developed, he can remove outerwear and shoes, uses the toilet and washes his hands. Help is needed to get dressed and put on his shoes. The boy enjoys attending school events, likes being around people. Emotional involvement in activities is minimal and the boy predominantly looks at his magazines. In relationships with adults, Georg is friendly, sociable, smiling, keen to make eye contact. Sometimes he shows a desire for direct body contact - he wants to sit on the teacher's lap and allows himself to be caressed. There is no communication with classmates and other students at school.

Georg has learned and successfully uses the lesson-plan - communication card system in his work. Good knowledge of daily activities shown with photos. Is always upset and surprised if something different happens.
Poorly developed fine finger muscles; with support can draw stencils, lines. Poorly perceives differences in letter contours. Partially mastered ability to differentiate colours, shapes, sizes. Georg has the skills to assemble simple puzzles of up to 20-30 pieces.

Georg's language is underdeveloped. There are some non-articulated sounds. Limited language understanding. Georg understands only very simple verbal instructions that are used more often in everyday life. Communication with the boy takes place using speech, combined with sign language. The boy imitates gestures very well, being able to relate them to a visible object or image. Georg has mastered the ability to use sign language gestures such as: thank you, bye, drink, eat, toilet visit, sleep.

Based on individual differences and observational results, criteria were selected to assess the growth of each student's vocabulary.

Maria will be judged on the process of both active vocabulary development and passive vocabulary development, using individual subject cards and storylines. Total word count: 76 nouns, 13 verbs, and 10 colour names.

Georg will be observed by the development of both active and passive vocabulary, the expressive expression of which will be expected - through the use of sign language gestures to visualise or understand words or actions perceived and understood by a visual analyser. Total word count: 64 nouns, 15 verbs, and 10 colour names.

Peter will also be observed in the process of developing vocabulary, both active and passive, whose expressive expressions will be expected - by perceiving and recognising real objects and simple images with the help of an auditory or visual analyser, using his sign language gestures. Total word count: 31 nouns, 9 verbs, 3 colour names.

Anna will have several criteria for assessing language perception and understanding, as well as passive vocabulary status.

The number of words already learned or to be learned is different for each student, and they were selected according to the principle that each student in the study group should understand or use the words during the year. The selection of these criteria took into account the means of expression that the learner is able to use, is trying to use, or would prefer to use.

For each student, in order to assess vocabulary volume or the criteria contributing to its impact, the Speech Therapist will use three skill levels to evaluate each criterion, with a score from 1 to 3 :

> 1 point (does not recognise; skill is not developed (for Anna)).

> 2 points (recognises, displays, but does not name or display the appropriate gesture; the word dominates in the passive vocabulary; skill is developed partially; sometimes; performed with help (for Anna)).

$>3$ points (recognises and names or displays the appropriate gesture; the word dominates in the active vocabulary; the skill is learned (for Anna)).

\section{Methods and activities used in the vocabulary enrichment process}

Intervention plans were created, taking into account the strengths and possibilities of each child. As the intellectual (cognitive) abilities of these four children are weak and limited, they have no interest in the world around them. These limitations affect the perception and production of language. Nevertheless, the Speech Therapist can do many things to promote their development.

Children with intellectual disabilities receive information through the senses; therefore, a multisensory approach was used in almost every session. Every Speech Therapy session started with a plan for it, and it was delivered in alternative ways. Photos, symbolic cards, and pictures were used. Firstly, the task or exercise was demonstrated as a cookie, the last activity - pleasant for every child after the main task. Sometimes it was something edible, or a balloon (for games with balloons to be carried out), or soap bubbles. Starting work with a small snack created positive emotions, and this was a stimulus for better involvement in activities. Children could also choose one or two activities to insert in the lesson plan. There was also the possibility to choose a prize. This gave an insight into the language development process; everything was discussed verbally, while also using gestures of sign language, alongside with pictures and photos. It was obvious that children with intellectual disabilities feel safer and more confident when the Speech Therapy sessions are planned and carried out with visual support.

Movement activities are of great importance in general development, as well as in the enrichment of vocabulary. Children with moderate or severe intellectual 
disabilities need support in different areas; visual, audial, kinaesthetic stimuli need to be mixed. Therefore, Speech Therapy sessions were reinforced with sign language exercises. Gestures were used to acquire names for objects (real or in pictures), for actions in combination with verbal cues. Children tried to repeat movements and point to the picture or object. When movements were used to indicate objects, actions or colours, small rhymes were used together with movements; later they were transformed into wonderful games promoting not only the development of vocabulary, but also mobility. When observing the production of rhymes by children, it was obvious that activities were performed with pleasure and interest. The Speech Therapist used not only sign language gestures, but also spontaneous movements, expressions, singing. At first, these rhymes were recited very slowly, thus it was easier for every child to follow and imitate the movements and words. At first - without verbal expression, only movements; later verbal expression was added as much as was possible for every child (some of them could only express some sounds). While some children produced sounds, others learned words and even short sentences. Listening is crucial for acquiring words, and this was also a part of the intervention. While listening to stories, children had to produce some movements for words, then they had to give answers by showing gestures, producing words, or pointing at the pictures. When working with children with moderate and severe intellectual disabilities, it is necessary to use all kinds of materials. Well-known examples are interactive books, where the text and information are supported by visual and audial signals. When a child touches a button, he can see a picture or hear a sound, a word or even a sentence. It is an interesting process for them, and listening skills are enhanced.

Although Anna has a severe intellectual disability and is not able to perceive audial information, she was also interested in listening, and therefore language perception was promoted. It was obvious that, when listening to a text, Anna was emotionally attached; the same applied to listening to music and producing movements together with the music. For this purpose, the girl's name was sung out in every Speech Therapy session. During this process, the girl's attention was attracted, she was listening, watching. It is one of the results - at the beginning of intervention, the girl did not pay attention to her name being pronounced out loud. At the end of the sessions, the girl was responding to her name almost every time. The intervention process for Anna was carefully planned to promote the development of cognitive processes (or at least to activate them), movements and tactile senses. The aim was to enrich the passive vocabulary with the words take, give, put.

The Speech Therapist's self-made games were used to manipulate objects and game elements - to grab, to release, put on, take off, connect, touch, and so on. The request was formed verbally, together with hand movements. Later Anna started to perform many activities on her own.

One of the most challenging goals of Anna's intervention process was to form the skill to ask for bread, water or music. As she likes bread very much, it was the first request to learn. The GoTalk communication board was used with a photo of bread. The girl had to push on the picture of bread, and every time she heard the word bread. Stimuli was a small piece of bread. Anna learned this very fast - by doing the action (pushing a button), she received something pleasant. The next step was a picture of bread, not on the GoTalk board. It was an attempt to use the acquired knowledge in a new situation. This was a difficult task and took longer, but it was successful anyway. Then the scheme was used to acquire the words water and music.

To promote the development of vocabulary for Maria and Georg, SymWriter, a symbol system of alternative communication, was used. SymWriter offers Vidgit symbols, where the written word has a visual symbol above it. It also offers the possibility to obtain an image of the whole word in block letters. Maria and Georg became acquainted with words and word combinations (noun and verb, noun and adjective). Using SymWriter, the Speech Therapist created her own games:

$>$ after verbal instruction by the Speech Therapist, the child has to find the appropriate symbol and has to say it, or show it with a sign language gesture;

$>$ a symbol is given to the child (or he chooses it by himself), and he has to name it, try to memorise it and show it with hand movements;

$>$ the Speech Therapist says a word combination of two words, and the child has to find it among different word combinations depicted by the Vidgit symbols;
> a word combination in Vidgit symbols is given to the child, and he has to pronounce each word, or show it by using sign language.

To promote the development of vocabulary as well as cognitive processes, different games and exercises were offered - games of construction, differentiation of colours, skills of visual perception and skills of comparing objects, pictures. It is necessary to change the tasks, to increase the level of difficulty step by step, to create variations of exercises (some elements are the same, but there are small changes). Thus, children can understand the rules of the game, and at the same time it helps to develop the skills to compare, to make a choice, to classify, to notice essential features, and to get the right answer.

For example, using the GoTalk board, different tasks were:

> the Speech Therapist points at similar objects in different colours; the child has to push the appropriate colour button, listen to the verbal name for it, try to pronounce it, or show it with a gesture;

> the Speech Therapist verbally names the word for a colour; the child has to find the visual form of this colour on the GoTalk board and push the appropriate button.

Before the next level of difficulty, the previous one was strengthened.

Finger games were used in every Speech Therapy session. There is a variety of finger games that enhances the agility and precision of movements - tilting, weaving, knotting, working with small objects, mosaics, natural materials, plastic masses, kinetic sand, and more. Nevertheless, children with moderate and severe intellectual disabilities are not able to play games; they need support to understand the essence of the game and its rules.

During the intervention process, different methods were used, and they interacted with one another. These were games and role play, together with alternative means of communication - pictures, photos, objects, Vidgit symbols, signs and gestures, and also different body and hand movements. As the perception of the involved children is limited, it was necessary to make sure that the process was pleasant for every child and adapted to their level of understanding.

\section{Results and Data Analysis}

To better assist children with moderate and severe intellectual disabilities to learn language and speech and to expand their 
vocabulary, both active and passive, the authors took into consideration all the circumstances that could affect the growth of the particular pupil in this area and devised a clear action plan: the most effective approaches and methods used to validate the effectiveness of the chosen methods between September 2018 and November 2019. Some of the used methods to facilitate the process of expanding the vocabulary of the pupils were specifically selected games, role play and exercises.

In order to positively influence the process of expanding the vocabulary of pupils in any of the Speech Therapy activities, first of all, great attention was paid to the environmental factor. In order to make the pupil feel safe and confident during lessons, every child's activity, whether successful or not, received positive comments, praise, and encouragement prizes, such as small stickers and badges.

Both the strengths and weaknesses of each pupil were identified, and their current and potential opportunities were identified; individual, appropriate requirements for each pupil were set.

In order to make work more productive in Speech Therapy classes, positive emotions were promoted, taking into account the individual characteristics and needs of each student, both encouraging and supporting their efforts with a variety of small prizes, in an effort to foster collaboration and build trust.

In every Speech Therapy session, in order to reach the set goal, in this case, expand the vocabulary of pupils, the Speech Therapist needs to provide the child with individual assistance. Being able to get help at the right moment created a sense of security in the student and added extra confidence to the Speech Therapist working with them. All these factors positively influenced the child's growth and were some of the factors that helped to achieve a good result in the vocabulary expansion process for all students in the study group.

In November 2019, a re-study was conducted to see how the correction work had progressed and what results had been achieved, using the same criteria as were used to determine the size of the students' vocabulary in the initial research. Data from the final study were compared with the results of the initial study.

When starting the evaluation of the words in Peter's active and passive gesture collection in September 2018, it was stated that the student had a very limited passive vocabulary. Out of the 43 words suggested, Peter did not recognise 36 of them. He could not show them by using gestures, but recognised 7 of them. During the initial research, it was found that the student had not yet understood the meaning of the gestures and their use in communication. There was a very limited understanding of language, but when the Speech Therapist was working, verbal information was accompanied by simple inviting gestures, such as Come on! Rise! The boy responded to these invitations.

One of the main tasks of the intervention was to acquire the ability to perceive and understand the meaning of the nouns and verbs that are more commonly heard in everyday life, as well as the ability to express their needs in a way that can be understood by others through sign language. Gestures were learned through various movement games, exercises, and role play (see Fig. 1).

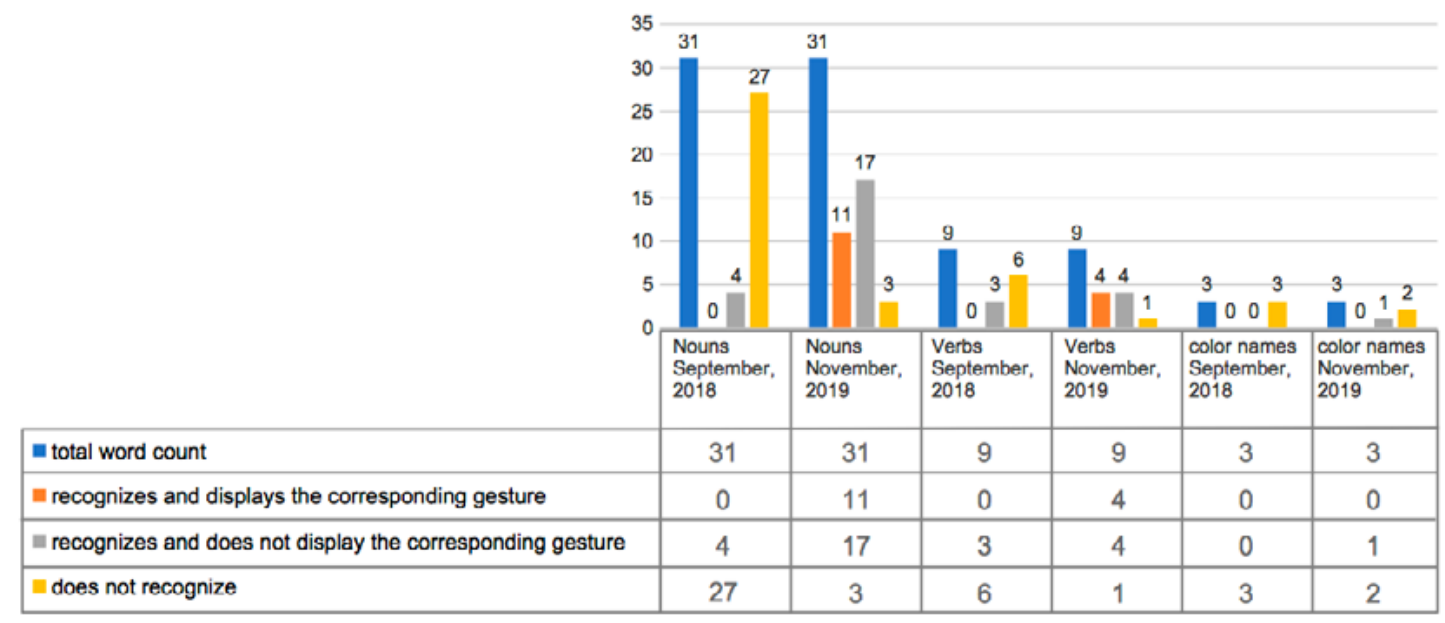

Figure 1: Peter's Active and Passive Gesture Collection and Passive Vocabulary Development Comparison for September 2018 and November 2019

The results of the re-study in November 2019, compared with the first-time data, confirm that the Speech Therapist has made considerable progress in the boy's vocabulary expansion process. Now, out of the 43 suggested words, there were only 6 words which the boy did not recognise. He did not understand the gestures, but understood the meaning of the gestures of 22 words. Not only did the boy recognise the 15 words (11 nouns and 4 verbs), he could display them by using appropriate gestures. So, as a result of the intervention, the boy has expanded both his passive vocabulary and active vocabulary and is able to understand the meaning of specific gestures, some of which he can show.

Georg's initial vocabulary test found that the boy's passive vocabulary contained 32 words out of 89 suggested words. For 4 verbs, George understood the meaning of the gestures that represented them and knew how to use the appropriate gestures.
With 53 words, the boy did not recognise or associate the audible sound with either the visual image in the pictures or the visual image of the gesture. The intervention with Georg was also intended to help him acquire the ability to perceive and understand the meaning of nouns and verbs commonly heard in everyday life, and to associate verbal signs of different colours with a particular gesture and, of course, to learn to communicate his needs with sign language gestures. In the initial test, 
the boy demonstrated not only the ability to imitate gestures, but also the ability to reproduce the 4 actions (eating, sleeping, drinking, and toileting) depicted in the pictures with a sign language gesture. In order to facilitate the development of this knowledge and to apply the acquired skills in everyday communication, the Speech Therapist used toys, games, exercises and Vidgit symbols in the learning process.
Through the active use of these techniques, over the course of the year, the pupil acquired the ability to understand and render most of the words offered by appropriate gestures (see Fig. 2).

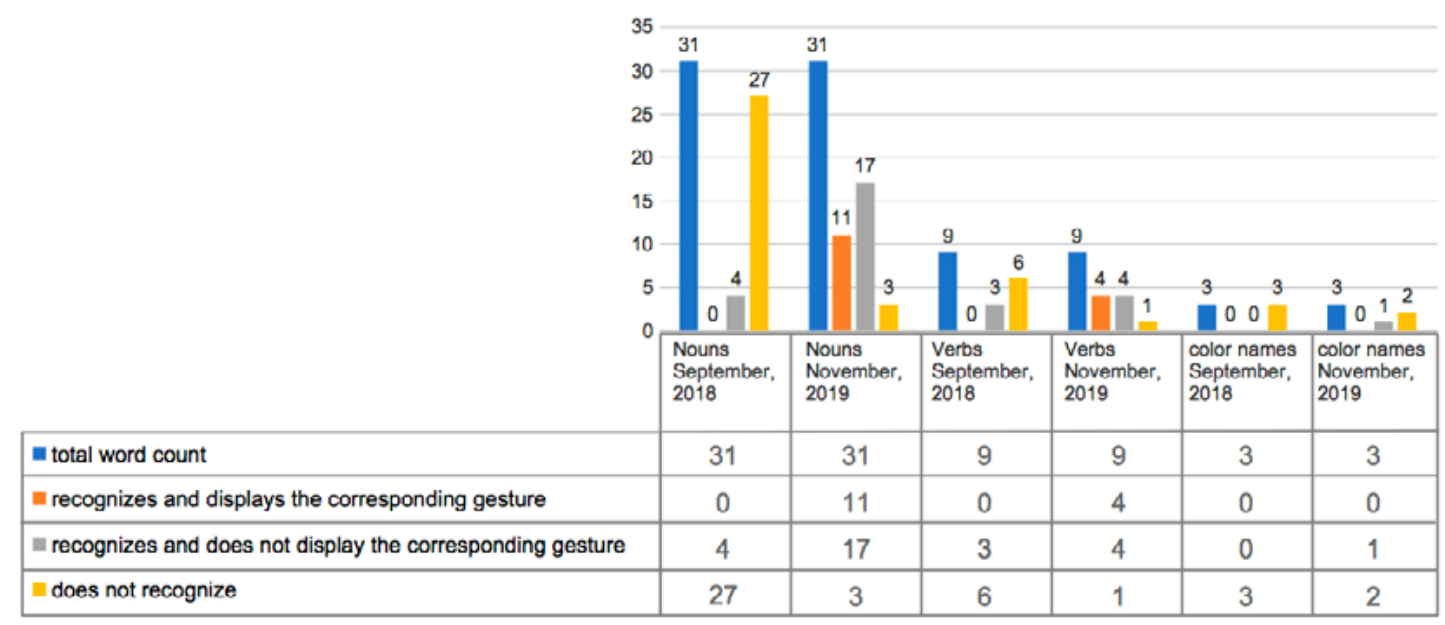

Figure 2: Georg's Active and Passive Gesture Collection and Passive Vocabulary Development Comparison for September 2018 and November 2019

Comparative data confirm that the boy now recognises and displays 66 words out of 89 words, recognises without displaying 22 words (these words are only in the passive vocabulary), but no longer recognises only 1 word. So, as a result of the intervention, Georg has also expanded his passive vocabulary, passive gestures and active gestures. $\mathrm{He}$ is able to understand the meaning of a relatively large number of gestures, many of which can also be shown by using hand movements.

Maria is able to use language in the communication process, but despite this, her vocabulary is relatively small, which makes it difficult for the girl to express herself to express her wishes qualitatively and to keep the conversation going. As soon as the girl has difficulty expressing herself, she becomes confused and begins to pronounce phrases that are often unrelated to the situation. During the initial research, the Speech Therapist concluded that, out of the 99 words offered, the girl had only 13 in her active vocabulary, 37 in her passive vocabulary, but 49 were not recognised. The girl had not developed the ability to associate the verbal notation of colour with the visual representation of colour perceived by the visual analyser, and thus she was unable to distinguish them by their names or to say what the name is for a particular colour. In order to promote the process of expanding vocabulary, both active and passive, Maria also chose to use sign language gestures as one of the leading working methods, incorporating them into various movement games, role play, exercises. After repeatedly researching the vocabulary, the Speech Therapist concludes that the chosen methods were a successful solution for the girl's vocabulary and expression skills (see Fig. 3).

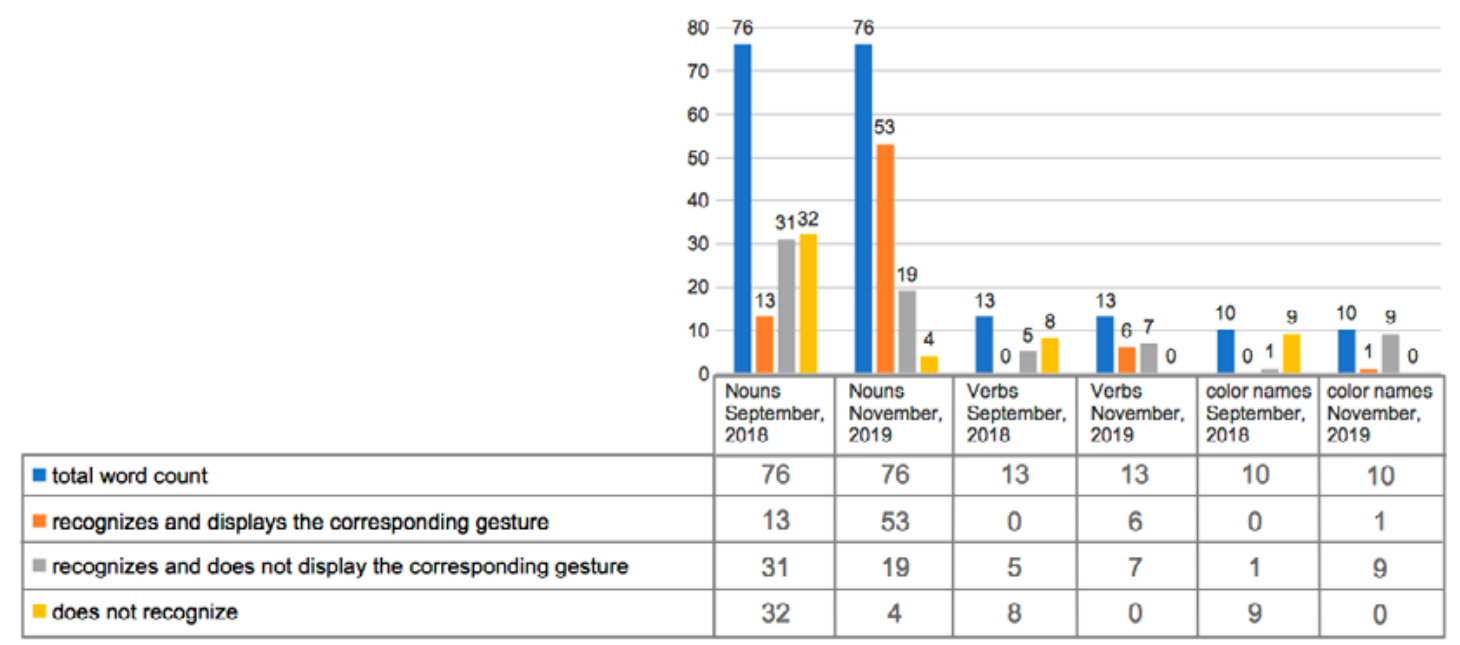

Figure 3: Maria's Comparative Data on the Development of the Active and Passive Vocabulary of Mary in September 2018 and November 2019 
In November 2019, after repeating the vocabulary volume research process and comparing the results with the first research data, it was obvious that the girl had made significant developmental progress in the process of active vocabulary development. Out of the 99 words offered, the girl is now able to recognise and name 60 , but her passive vocabulary contains 35 words. The girl has not mastered 4 words yet. As a result, both the passive vocabulary and the active vocabulary have expanded as a result of the intervention work. Maria has finally mastered the ability to associate the verbal designation of a colour with a specific gesture of sign language, which is a great achievement for her, as colour names have so far been abstract concepts.

Anna has a severe intellectual disability. Through initial research on language perception, comprehension and passive vocabulary, the Speech Therapist was able to observe how poorly the girl's ability to

perceive and understand language was developed. Her passive vocabulary was very limited, practically non-functional. The girl did not react to the sound of her name, did not understand and did not respond to simple instructions - neither gestures nor words. She could not use any means of expression in communication. Taking into account the girl's poor development and insufficient skills, the Speech Therapist set a goal - to stimulate language perception and comprehension and to try to expand the passive vocabulary with subject and action names important to the girl - bread, bubbles, music (referring to a synthesizer), drink, eat, rise, sit, let's go, take, and to learn how to ask for bread or a drink. To achieve this goal, the Speech Therapist chose the following methods - use of alternative communication tools (bread, mug and synthesizer images), GoTalk communication board, use of inviting gestures and verbal guidance, movement games, sensory exercises (see Fig. 4 ).

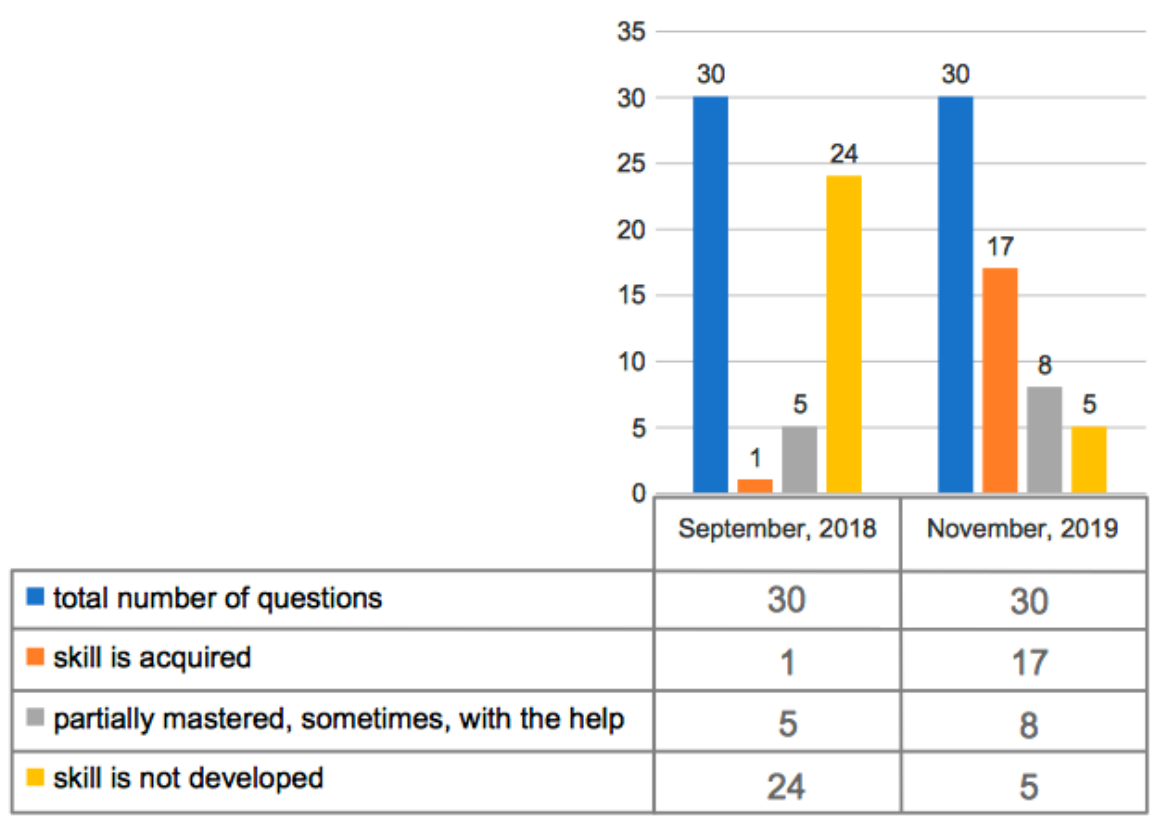

Figure 4: Benchmarking of Anna's Language Perception and Understanding, Communication Process and Passive Vocabulary in September 2018 and November 2019

Comparing the results obtained in November 2019 with those obtained in September 2018, the Speech Therapist concludes that there is also an increase in the development of Anna's language perception, comprehension and passive vocabulary. The initial study found that, out of the 30 suggested questions that testify to the girl's ability to perceive and understand language - with the grade 'skill acquired' - only 1 question could be evaluated, but 17 questions received this grade in November 2019. So, as a result of the intervention, the girl has mastered the skill of asking for the coveted snack - bread which is a great achievement in itself. She has an improved ability to understand both simple pointing and inviting gestures and verbal cues.

\section{Conclusions}

Despite the extent to which each of these pupils had mastered their language perception and expression skills, this study demonstrated that purposeful and active use of Speech Therapy classes allowed them to undergo the vocabulary expansion process - according to the type of communication possible for each student. Both active vocabulary and passive vocabulary were enriched, as well as the ability to understand and use sign language gestures in the communication process. These results were achieved by using games, role play and exercises, alternative communication tools and sign language gestures. This study confirms that any language can be represented in a visual way. If necessary, the vocabulary of any language can be expanded through a variety of visually perceived alternative means of communication, both in the form of images and symbols, and the meaning of words in motion, sign language gestures. In the process of enriching vocabulary by acquiring the ability to associate a vocally perceived word with a realistic image, symbol or gesture, the use of specifically selected games, role play and exercises is the most productive method.

Speech and language are closely related to human cognitive processes and there is a close interaction. Vocabulary enrichment plays an important role in the development of children (including those with moderate to severe intellectual disabilities); it enhances their intellectual capacity. With the help of language, the child learns about what is happening around him.

The quantitative and qualitative expression of a child's language is significantly influenced not only by the environment in which he grows and develops, but also every moment when the baby is still in his mother's womb. No less important is the moment when a baby announces himself by the first cry in this world, as well as the subsequent years of life until the child is able to begin school. Language disorders have a negative impact on a child's character and behaviour, as only language can express their thoughts, feelings, requests and attitudes towards different forms of behaviour.

Vocabulary volume is very important for a child's ability to communicate fully and to explore the world as he develops. The ability to use language - to understand what others are saying and to be able to express themselves - is a very important component in the communication process. Children, whether they have developmental disabilities or not, are only able to perceive and understand the part of verbal information that is easily perceived, explained or, where necessary, appropriately 
formulated. Expanding the vocabulary plays a very important role in the personality development process in students with intellectual disabilities. Even if only slightly enriched, it opens up opportunities for these children to become more active in exploring the world around them and helps them to integrate more easily into social life.

Intellectual disabilities affect the personality as a whole. One of the most prominent features is the lower than average intelligence, whose developmental deficiencies are predominantly seen in everyday life, in communication, in self-care, and in the acquisition of academic skills. Children with intellectual disabilities are able to develop only within the limits of their abilities, which undoubtedly depends on the extent to which the child's mental capacity is impaired, such as impaired thinking, memory, perception and language.

Professionals working with these children, including the Speech Therapist, require a great deal of patience to achieve even insignificant progress in a skill area, because despite moderate or severe developmental disabilities, students can learn different skills. This only requires a very long time.

It is only through practical action that all skills and abilities are developed, and that what is learned is deepened and strengthened. This means that, in order to form and consolidate in the child's mind the new words that denote things and actions, as well as events that take place around him, he needs to taste, smell, touch, look, and listen to the world.

The Speech Therapist as a specialist must be a creative person who is not afraid to experiment with different methods and techniques, nor with the choice of teaching aids. No theorist or practitioner is able to provide a uniform, constant formula of how to expand the vocabulary of pupils who have moderate or severe intellectual disabilities, because each of these pupils is different, each has their own strengths and weaknesses, each develops at his own pace, and the method that suits one of them often turns out to be completely useless for another.

It is the play activity that reveals any deviation, if any, in a child's personality development. With the aid of the toy, it is possible to correct any child's developmental disorder, any hindrance or lack of skills. The dynamics of language development can be promoted through the direct use of a variety of movement activities, including teaching, play and games. In addition, various types of exercises that promote mobility and coordination of movement, sensory abilities, and language and speech skills would also help to develop constructive interpersonal skills. Through movement, children learn and remember information more easily, because it is memorised through associative perception. Specifically, the word perceived by the hearing analyser is learned through interaction with the movement perceived by the vision analyser.

If the Speech Therapist reinforces the spoken word by some alternative means of communication, it will not only improve the student's vocabulary, but also improve his language perception and ability to express his needs. The Speech Therapist should improve the language of the non-speaking pupil by either the language of images or the language of hand-to-finger movement.

In pupils with moderate to severe intellectual disabilities, language disorders are very severe and widespread. However, the Speech Therapist must do his/her utmost to facilitate the development of these students in this area as well. The richness of passive and active vocabulary in children with moderate to severe intellectual disabilities, who are able to express their needs at least a little with verbal means of expression, and the passive vocabulary of children who have not developed their vocabulary, also influences how they develop their cognitive activity, cognitive abilities, thinking and memory characteristics.

For students with moderate to severe intellectual disabilities, each improvement is accomplished with great effort, including the vocabulary expansion process. Therefore, the Speech Therapist must be supportive of each child's achievement when working with these children. Positive reinforcement of a variety of pleasurable emotions, such as expressing appreciation for a job well done, praise, a fun activity at the end of a Speech Therapy session, treats, etc., should be used regularly to stimulate motivation.

Expanding the vocabulary of pupils through Speech Therapy helps to build children's self-esteem, helps them to believe in their own abilities.
If the language and speech skills of these children are so limited in their expression that they are unable to develop or enhance the communication process, then the primary task of the Speech Therapist is to promote the child's ability to understand the world around him and to express his desires and needs, using an alternative language that is either sign language gestures, pictograms, pictures, photos, or various symbol systems, such as Vidgit images provided by SymWriter. Conversely, if these children have developed or are beginning to develop speech and language, such as individual sounds, syllables, words, then it is highly desirable to improve the process of language and speech development, including vocabulary expansion, by acquiring the ability to use active spoken communication in combination with various means of alternative communication.

Pupils with severe intellectual disabilities feel more confident about their abilities when their life activities, including Speech Therapy activities, are planned in a visual way. Toys, exercises, and games play an important role in the learning process in order for the child to succeed in his developmental growth. Without support, they will not be able to understand the nature of toys, or games and their rules. Therefore, a Speech Therapist working with these children should teach them the play process, how to play games and how to perform exercises.

The vocabulary of any language can be expanded through a variety of visually recognisable alternative means of communication, both in the form of images and symbols, and the meaning of words in motion, the sign language gestures.

Research proves that it is possible to extend the vocabulary in students with moderate to severe intellectual disabilities. On the other hand, the most effective methods to use in this process are games, role play, exercises and alternative communication tools, such as pictures, symbols and sign language gestures.

All students in the study group made significant progress in the vocabulary expansion process. This leads to the conclusion that there is a need to continue to set new goals that will further advance these students' progress in vocabulary development. 


\section{References}

AKHTAR, N., \& GERNSBACHER, M. A., 2007. Joint Attention and Vocebulary Development: A Critical Look. In: National Institute of Health Public Access - Lang Linguist Compass. 2007 May; 1(3): 195-2017. DOI: 10.1111/j.1749-818X.2007.00014.x.

ALLER, E. E., 2017. Developmental Impact of Inclusion Classrooms on Autism Spectrum Disorder: A Systematic Review. Sophia: St. Catherine University repository. Retrieved from: https://sophia.stkate.edu/msw_papers/697

American Psychiatric Association. (2018). Retrieved from: https://www.psychiatry.org/psychiatrists/practice/dsm/updates-to-dsm -5/coding-updates

BONETE, S., MOllinero, C., MATA, S., CALERO, M. D. \& GOMEZ-PEREZ, M del M., 2016. Effectiveness of Manualised Interpersonal Problem-solving Skills Intervention for Children with Autism Spectrum Disorder (ASD). In: Psicothema. Vol. 28, No. 3, 304-310. DOI: 10.7334/psicothema2015.206.

BORNSTEIN, M. H., HAHN, C-S., PUTNICK, D. L., \& PEARSON, R. M., 2018. Stability of core language skill from infancy to adolescence in typical and atypical development. In: Sci. Adv. 2018; 4:eaat7422. 21 November 2018. Available: http://advances.scien cemag.org/. Retrieved: 23. 03. 2020.

DA FONTE, M. A., \& BOESCH, M. C., 2018. Effective augmentative and alternative communication practices: Description. New York: Routledge.

ESLER, A. N. \& RUBLE, L. A., 2015. DSM-5 Diagnostic Criteria for Autism Spectrum Disorder With Implications for School Psychologists. In: International Journal of School and Educational Psychology. Vol. 3, Issue 1. DOI: 10.1080/21683603.2014.890148.

FRYE, R. E. \& BEUCHAMP, M. S., 2009. Receptive Language Organization in High-Functioning Autism. In: Journal of Child Neurology. Vol. 24, No. 2, 231-236. DOI: 10.1177/0883073808329572.

FTEIHA, M. A., 2016. Effectiveness of assistive technology in enhancing language skills for children with autism. In: International Journal of Developmental Disabilities. DOI: 10.1080/20473869.2015.1136129.

GEIDŽS, N. L, \& BERLINERS B. C., 1998. Pedagoǵiskā psihologija [Pedagogical Psychology]. Rīga: Zvaigzne ABC.

GILES, Br. (ed.), 2002. Thinking and Knowing. London: Grange Books.

GIRIMAJI, S. C., \& PRADEEP, A. J., 2018. Intellectual Disability in International Classification of Diseases-11: A Developmental Perspective. In: Indian J Soc Psychiatry. 2018; 34: S68-74 Available: http://www.indjsp.org. Retrieved: 20. 03. 2020.

HEMPHILL, L., \& TIVNAN, T., 2008. The Importance of Early Vocabulary for Literacy Achievement in High-Poverty Schools. In: Journal of Education for Students Placed at Risk. November, 2008. DOI: 10.1080/10824660802427710.

HILLIS, A. E., 2001. The Organization of the Lexical System. In: Brenda Rapp (ed.). The Handbook of Cognitive Neuropsychology: What Deficits Reveal About the Human Mind. John Hopkins University. USA: Printed by Edwards Brothers, p. 185-210.

JELLIFFE-PAWLOWSKI, L. L., SHAW, G. M., NELSON, V., \& HARRIS, J. A., 2003. Risk of Mental Retardation Among Children Born With Birth Defects. In: ARCH Pediatr Adolesc Med/. Vol. 157, June 2003 Available: https://jamanetwork.com/. Retrieved: 23. 03.2020.

KARVELIENE, R., 2019. Empowerment of students in disability situation to participate in international activities of higher education. Šiauliai: Šiauliai University.

KOENIG, K. P., FELDMAN, J. M., SIEGEL, D., COHEN, Sh. \& BLEIWEISS J., 2014. Issues in Implementing a Comprehensive Intervention for Public School Children With Autism Spectrum Disorders. In: Journal of Prevention \& Intervention in the Community. Vol. 42, Issue 4, 248-263. DOI: 10.1080/10852352.2014.943638.

KL,AVIN̦A, S., 1997. Valodas daba [The Nature of the Language]. Rīga: Lielvārds.

KORKMAZ, B., 2011. Theory of Mind and Neurodevelopmental Disorders of Childhood. In: Pediatric Research. Vol. 69, No.5. Pt. 2, 2011 0031-3998/11/6905-0101R.

KÜLE, M., \& KŪLIS, R., 1998. Filozofija [Philosophy]. Rīga: Zvaigzne ABC.

LANDRĀTE, E., \& TŪBELE, S., 2019. Autisms un saskarsme [Autism and Communication]. Rīga: RaKa.

LAUA, A., 1981. Latviešu leksikologiija [Lexicology of Latvian language]. Rīga: Zvaigzne.

LIEPIN̦A, S., 2008. Speciālā psihologija [Special Psychology]. Rīga: RaKa.

LŪSE, J., MILTIN̦A, I., \& TŪBELE, S., 2012. Logopēdijas terminu skaidrojošā vārdnīca [Glossary of Speech Therapy Terms]. Rīga: RaKa.

MARJANOVIČ-UMEK, L., FEKONJA-PEKLAJ, U., \& PODLESEK, A., 2012. Characteristics of early vocabulary and grammar development in Slivenian-speaking infants and todlers: a CDI-adaptation study. Open Access. DOI: 10.1017/S0305000912000244.

MARRUS, N., \& Hall, L., 2018. Intellectual Disability and Language Disorder. In: Child Adolesc Psychiatr Clin. DOI: 10.1016/j. chc.2017.03.001. 
MCKENZIE, R. \& DALLOS, R., 2017. Autism and attachment difficulties: overlap of symptoms, implications and innovative sollutions. In: Clinical Child Psychology and Psychiatry. Vol. 22(4) 632-648. DOI: 10.1177/1359104517707323.

MILTIN,A, I., 2008. Skolotāja logopēda darba mape [Portfolio of Teacher Speech Therapist]. Rīga: RaKa.

MILTIN,A, I., 2019. Saistītās runas pilnveidošana [Development of the Connected Speech]. Rìga: RaKa.

MOODY, S., HU, X., KUO, L., JOUHAR, M., XU, Z., \& LEE, S., 2018. Vocabulary Instruction: A Critical Analysis of Theories, Research, and Practice. In: Educational Sciences. 2018, 8, 180. DOI: 10.3390/educsci8040180.

O'BRIEN, G. \& PEARSON, J., 2004. Autism and learning disability. In: Sage Publications and The National Autistic Society. Vol. 8(2) 125-140. Retrieved from: http://citeseerx.ist.psu.edu/viewdoc/download?doi=10.1.1.819.3956\&rep=rep1\&type=pdf

PEREPA, P., 2014. Cultural basis of social 'deficits' in autism spectrum disorders. In: European Journal of Special Needs Education. Vol. 29, Issue 3, 313-326. DOI: 10.1080/08856257.2014.908024.

PRUDN̦IKOVA, I., 2012. Skolēnu ar vidēji smagiem un smagiem garīgās attīstības traucējumiem praktiskās darbības pieredzes veidošanās speciālajā internätpamatskolā [Formation of practical experience of pupils with moderate and severe intellectual disabilities in special boarding school]. Rēzekne: Rēzeknes augstskola.

PRUTHI, G., 2013. Language Development in Children With Mental Retardation. Available: http://dynapsyc.org/2013/LanguageDevelop ment.pdf. Retrieved: 29. 02. 2020.

REAGAN, N., 2012. Effective Inclusion of Students with Autism Spectrum Disorders. Education Masters. Paper 276. Retrieved from: https://fisherpub.sjfc.edu/education_ETD_masters/276/

SHIH, W., PATTERSON, S. Y. \& KASARI, C., 2016. Developing an Adaptive Treatment Strategy for Peer-Related Social Skills for Children with Autism Spectrum Disorders. In: Journal of Clinical Child \& Adolescent Psychology. Vol. 45, Issue 4, 469-479. DOI: $10.1080 / 15374416.2014 .915549$.

SHREE, A., SHUKLA, P. C., 2016. Intellectual Disability: definition, classification, causes and characteristics. In: Learning Community. 7(1) 9-20 April, 2016. DOI: 10.5958/2231-458X.2016.00002.6

SCHWARTZ, R. G., 2017. Handbook of child language disorders. Second edition. New York: Routledge.

SHORT, K., EADIE, P., \& KEMP, L., 2019. Paths to language development in at risk children: a quaitative comparative analysis (QCA). In: BMC Pediatrics. (2019) 19:94. DOI: 10.1186/s12887-019-1449-z.

SINGLETARY, W. M., 2015. An integrative model if autism spectrum disorder: ASD as a neurobiological disorder of experienced environmental deprivation, early life stress and allostatic overload. In: Neuropsychoanalysis: An Interdisciplinary Journal of Psychoanalysis and the Neurosciences. Vol. 17, Issue 2, 81-119. DOI: 10.1080/15294145.2015.1092334.

SONG, J. Y., DEMUTH, C., \& MORGAN, J., 2018. Input and Processing Factors Affecting Infants Vocabulary Size at 19 and 25 Months. In: Frontiers in Psyhology. 9:2398. DOI: 10.3389/fpsyg.2018.02398.

TAYLOR, B. A. \& DEQUINZIO, J. A., 2012. Observational Learning and Children with Autism. In: Behavior Modification. 36(3) 341-360. DOI: $10.1177 / 0145445512443981$.

TŪBELE, S., 2019. Valodas traucējumu novērtēšana [Evaluation of Speech Disorders]. Rīga: RaKa.

VIGOTSKIS, L,., 2002. Domāšana un runa [Thinking and Language]. Rīga: Eve.

VIVANTI, G., 2017. Individualizing and Combining Treatments in Autism Spectrum Disorder: Four Elements for a Theory-Driven Research Agenda. In: Current Dirrections in Psychological Science. Vol. 26(2) 114-119. DOI: 10.1177/0963721416680262.

ZUBRICK, S. R., TAYLOR, C. L., \& CHRISTENSEN, D., 2015. Patterns and Predictors of Language and Literacy Abilities 4-10 Years in the Longitudinal Study of Australian Children. In: PLoS ONE. 10(9). DOI: 10.1371/journal.pone.0135612. 